\title{
A relação público-privada em uma região de saúde: influências sobre a organização da oferta e da demanda de média complexidade no Sistema Único de Saúde em pequenos municípios The relation between public and private in a health region: influences on the organization of medium complexity supply and demand in small municipalities served by the Brazilian National Health System
}

João Felipe Marques da Silva ${ }^{a}$

(1) https://orcid.org/0000-0001-7198-8528

E-mail: jmfliperøhotmail.com

\section{Brígida Gimenez Carvalho ${ }^{\mathrm{a}}$}

(1) https://orcid.org/0000-0003-3850-870X

E-mail: brigidagimenezळgmail.com

\section{Carolina Milena Domingos ${ }^{\mathrm{a}}$}

(D) https://orcid.org/0000-0002-7725-1831

E-mail: carolinamdomingos $\bowtie$ gmail.com

Fernanda de Freitas Mendonça ${ }^{a}$

(1) https://orcid.org/0000-0002-3532-5070

E-mail: fernanda0683ळgmail.com

aniversidade Estadual de Londrina. Programa de Pós-Graduação em Saúde Coletiva. Londrina, PR, Brasil

\section{Correspondência}

João Felipe Marques da Silva

Av. Robert Koch, 60, Vila Operária. Londrina, PR, Brasil.

CEP 86057-970.

\section{Resumo}

0 artigo analisa como a relação entre gestores públicos de saúde e prestadores do sistema privado complementar influencia a organização da oferta e demanda de ações e serviços de média complexidade (ASMC) em uma região de saúde formada por municípios pequenos. Trata-se de estudo de caso de natureza qualitativa realizado entre dezembro de 2016 e fevereiro de 2017. Os resultados apontam que a influência da relação entre gestores e prestadores na oferta e demanda de ASMC está relacionada a características envolvidas em três categorias principais: a assistência médica especializada, a contratualização dos serviços e a gestão do sistema. Dentre as características das categorias mencionadas destacam-se a "reserva de mercado" por um grupo fechado de profissionais médicos e prestadores, contratos executados à revelia das normas do sistema e o fato de os profissionais médicos da rede pública serem os próprios prestadores privados das ASMC na região. A influência da relação público-privado na organização da oferta e demanda prioriza recursos municipais para as ASMC e demonstra a fragilidade do processo de regionalização e do papel do ente estadual. Neste contexto, a atenção básica revela-se como política preterida à administração pública.

Palavras-chave: Relação Público-Privada; Média Complexidade; Regionalização; Gestão em Saúde. 


\section{Introdução}

This study analyzes how the relation between public health managers of small municipalities (SMs) and providers of the supplementary private system influences the organization of supply and demand of medium complexity actions and services (ASMC) in a health region formed by small municipalities. This is a qualitative case study conducted from December 2016 to February 2017. The results show that the influence of the relation between managers and providers in the supply and demand of ASMC is related to characteristics involved in three main categories: specialized medical care, contracting of services, and system management. Among the characteristics of the categories mentioned are the "market reserve" by a closed group of medical professionals and providers; contracts executed according to the system rules; and the fact that public health medical professionals are the private providers of ASMC in the region themselves; among others. The influence of the relation between public and private on the organization of supply and demand prioritizes municipal resources for ASMC and demonstrates the fragility of the health region planning process and the role of the government. In this context, primary health care is revealed as a policy neglected by public administration Keywords: Public-Private Relations; Medium Complexity; Regional Health Planning; Health Management.
A assistência médica privada sempre participou da organização da política de saúde brasileira, com influência progressiva na oferta e na estrutura dos serviços nacionais (Carvalho et al., 2017). Esta participação teve diferentes impactos no modelo de saúde vigente no país, dentre eles, a complementariedade de serviços privados no Sistema Único de Saúde (SUS) (Brasil, 1990).

$\mathrm{Na}$ atenção de média complexidade, a oferta depende fortemente do setor privado, mesmo após a implantação do SUS, devido à insuficiência da rede pública para o atendimento dos usuários, mantendose nesta área a lógica de compra de ações e serviços de maneira complementar (Brasil, 1990).

Somam-se a este contexto os investimentos realizados pelo Ministério da Saúde na última década em ações, programas, e serviços da Atenção Básica (AB) nos municípios brasileiros. Isso contribui para a ampliação do acesso e consequente aumento dos diagnósticos e tratamentos dos agravos, resultando em maiores demandas às ações e serviços de média complexidade (ASMC) (Silva; Carvalho; Domingos, 2018).

Atualmente, as ASMC são caracterizadas como um dos grandes desafios para a organização do SUS, sobretudo pelas inúmeras diferenças relacionadas ao acesso deste nível de atenção nas regiões de saúde do país, o que compromete diretamente as bases legais do sistema, pois este nível de complexidade concentra expressiva importância na garantia do direito à saúde dos usuários (Spedo; Pinto; Tanaka, 2010).

Mendes (2019) menciona, como outro grande desafio, a falta de pesquisas na área, quando comparada à produção científica em atenção primária e assistência hospitalar, e destaca a importância de estudos para que os problemas sejam solucionados de forma mais racional.

Neste cenário, Lima et al. (2019) apontam que a oferta de ações de média complexidade ambulatorial e hospitalar nas regiões de saúde do Brasil são realizadas por estruturas híbridas (públicas e privadas), com predominância do prestador público municipal na esfera ambulatorial, e do prestador privado filantrópico na área hospitalar.

No entanto, cerca de 70\% dos municípios brasileiros que compõem as regiões de saúde são de pequeno 
porte (MPP) (Brasil, 2004), possuem baixa capacidade instalada (Spedo; Pinto; Tanaka, 2010) e baixa arrecadação fiscal (Trevisan; Junqueira, 2007). Esses fatores condicionam tanto a oferta quanto a compra de serviços pelo ente municipal.

Em algumas regiões, a depender do modo em que se definiram as responsabilidades de gestão dos entes governamentais após o processo de descentralização do SUS, a oferta destes serviços pode estar sob a responsabilidade de municípios polo e do ente estadual (Lima et al., 2019).

Dados de pesquisas empíricas demonstram que gestores de MPP também se responsabilizam pelo custeio destas ações, uma vez que os serviços disponíveis pelos municípios polo e/ou pelo ente estadual não suprem a necessidade de atenção de seus munícipes. Assim, necessitam de uma frequente relação contratual com prestadores privados para a garantia da oferta, o que constitui a relação público-privada desta esfera de gestão (Silva; Carvalho; Domingos, 2018).

Outros determinantes ainda revelam-se como influentes para a oferta das ASMC, entre eles: a organização das redes de atenção e do processo de regionalização (Viana et al., 2017); a distribuição de profissionais médicos especialistas e aspectos da sua formação e atuação (Scheffer, 2018); a regulação clínicoassistencial e a organização e dimensionamento de tecnologias no território (Mendes, 2019); a ausência de espaços de negociação entre o público e o privado nas regiões brasileiras (Viana et al., 2017); e as permanentes relações constituídas entre gestores públicos e prestadores privados (Menicucci, 2003; Silva; Carvalho; Domingos, 2018).

Pelo apresentado, considera-se que a trajetória das políticas de saúde no Brasil possibilitou incentivos à organização de grupos de interesse sobre o financiamento público e produz constrangimentos institucionais que modelam os comportamentos de atores sociais e políticos envolvidos nos processos de execução das políticas de saúde. Essa situação reforça as consequências políticas e institucionais iniciais e cria determinada rigidez às instituições (Menicucci, 2003).

Esta concepção filia-se ao referencial teórico da corrente "neoinstitucionalista histórica" (Pierson, 2004), e é oportuna para analisar a influência da relação entre gestores públicos de saúde de MPP e prestadores do sistema privado complementar quanto à organização da oferta e demanda de serviços de média complexidade em uma região de saúde do Paraná, objetivo deste estudo. Cabe destacar que a relação público-privada será analisada sob três dimensões: assistência médica especializada; contratualização de serviços; e gestão do sistema.

\section{Procedimentos metodológicos}

Trata-se de um estudo de caso de natureza qualitativa, realizado em uma região de saúde formada por 16 MPP, localizada na macrorregião norte do Paraná. Essa região possui indicadores (renda domiciliar e produto interno bruto per capita, número de médicos por mil habitantes, e porcentagem de beneficiários de planos de saúde, entre outros) que a classificam como a única do Paraná com baixo desenvolvimento socioeconômico e baixa oferta de serviços de saúde. ${ }^{1}$ A insuficiência da oferta é observada, por exemplo, na comparação entre o número de médicos especialistas da região e a quantidade necessária conforme a Portaria $n^{0} 1.631 / 2015$ (Brasil, 2015) (Tabela 1).

Tabela I - Número de especialistas e a necessidade de médicos por especialidade, conforme parâmetros de planejamento da Portaria GM/MS n 1.631/2015, região de saúde do Paraná, 2017

\begin{tabular}{lcc}
\multicolumn{1}{r}{ Especialidade } & N de especialistas existentes* & Necessidade de especialistas** $^{* *}$ \\
Cinecologista/Obstetra & 7 & 34,5 \\
Pediatra & 2 & 34,5 \\
Acupunturista & 0 & 1,5 \\
Alergista & 0 & 1,5 \\
Angiologista & 0 & 2 \\
Cardiologista & 3 & 9 \\
\hline
\end{tabular}

REGIÃO E REDES: caminhos para a universalização da saúde no Brasil: banco de indicadores regionais e tipologias, 2016. Disponível em: http://www.resbr.net.br. Acesso em: 27 fev. 2016. 


\section{Tabela I-Continuação}

\section{Especialidade}

$\mathrm{N}$ de especialistas existentes*

Necessidade de especialistas**

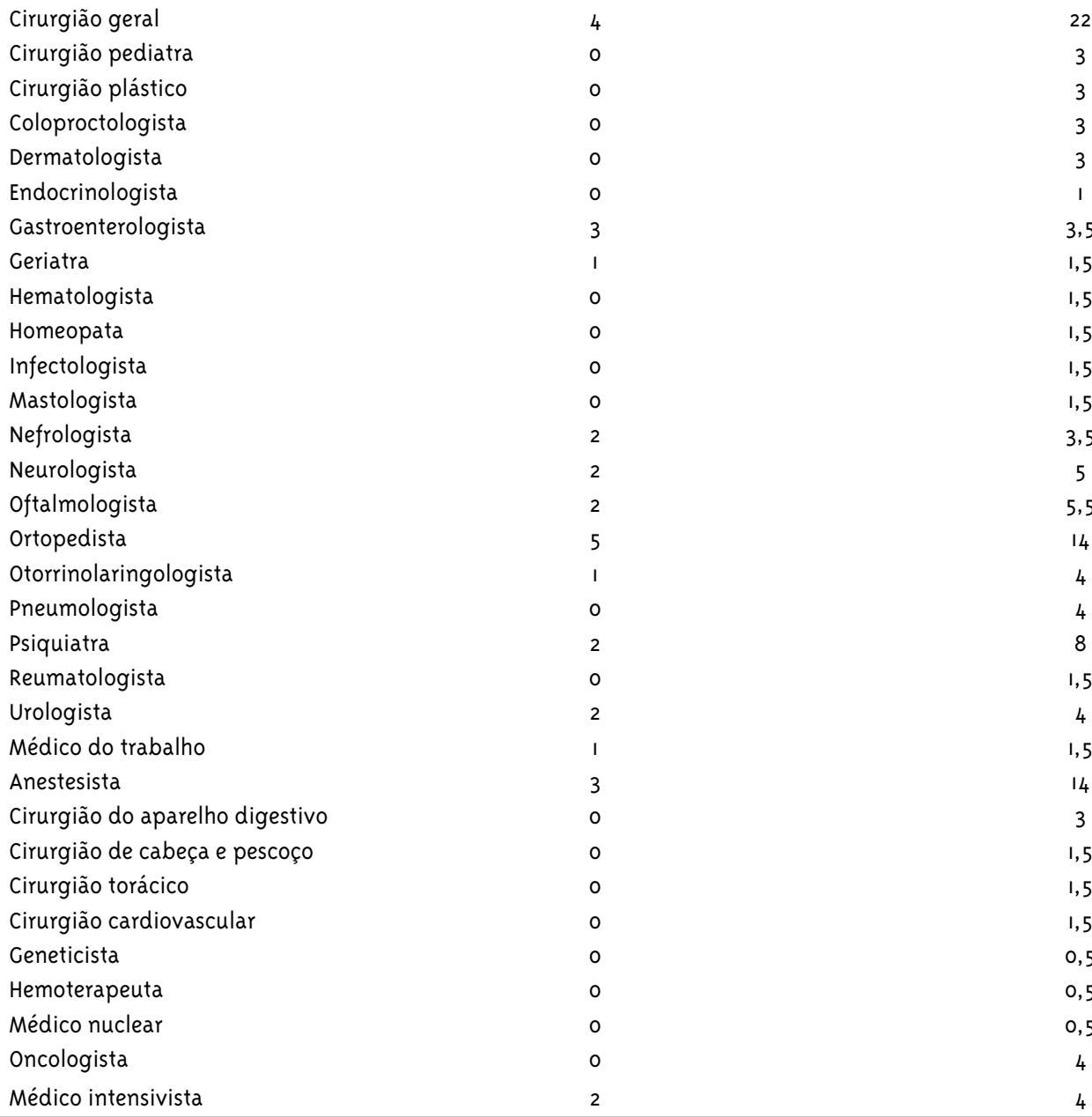

Fonte: ${ }^{*}$ Dados disponíveis no Cadastro Nacional de Estabelecimentos de Saúde. ${ }^{2 *}$ Cálculo baseado na população regional considerando a Portaria GM/MS $n$ I.631/2015 (Brasil, 2015)

Para obtenção dos dados fez-se entrevistas orientadas por um roteiro semiestruturado, entre dezembro de 2016 e fevereiro de 2017 , com 9 sujeitos: 4 gestores municipais de saúde; 1 representante da Secretaria Estadual de Saúde Regional (Sesa); 1 representante, apoiador do Conselho de Secretários Municipais de Saúde (Cosems); 1 representante do Consórcio Intermunicipal de Saúde (CIS), e 2 gestores de hospitais privados da região (Tabela 2).
Tabela 2 - Distribuição da amostra de pesquisa, região de saúde do Paraná, 2017

\section{Estrato populacional $\quad \mathrm{N}$ de municípios $\mathrm{N}$ de entrevistas}

\begin{tabular}{lll} 
"5.000 habitantes & 7 & 1 \\
$5.001-10.000$ habitantes & 3 & 1 \\
$10.001-20.000$ habitantes & 5 & 1 \\
"20.001 habitantes & 1 & 1 \\
\hline & & continua...
\end{tabular}

2 BRASIL. Cadastro Nacional de Estabelecimentos de Saúde: consulta de estabelecimento: competência janeiro 2017.2017. Disponível em: <http://cnes.datasus.gov.br/>. Acesso em: 9 maio 2020. 


\section{Tabela 2-Continuação}

Demais sujeitos

Representante da Sesa regional

Representante do Cosems

Representante do CIS

Prestadores privados

Total

Sesa: Secretaria Estadual de Saúde Regional; Cosems: Conselho de Secretários Municipais de Saúde; CIS: Consórcio Intermunicipal de Saúde.

Para a definição da amostra dos gestores de saúde, os municípios da região foram classificados em quatro estratos populacionais (Tabela 2), selecionando-se de forma intencional um sujeito de cada estrato.

0 representante estadual foi inserido na amostra devido à intermediação contratual que executa entre os prestadores e o nível central da Sesa; o representante do consórcio pela oferta de serviços de média complexidade; e o apoiador do Cosems devido à articulação técnico-política com a região de estudo.

Selecionou-se prestadores hospitalares por entender que a relação público-privada, na região, é mais evidente nestas instituições. Os gestores dos dois únicos hospitais privados da região integram a pesquisa. As instituições privadas são de médio porte, conveniadas ao SUS, possuem especialidades médicas variadas e densidade tecnológica intermediária para diagnose e intervenção. Estas foram as características consideradas como critérios de inclusão dos entrevistados.

As entrevistas foram gravadas e transcritas, e o texto, submetido à análise de discurso proposta por Martins e Bicudo (2003). A análise foi realizada em duas etapas: a ideográfica, ou análise individual, mediante a leitura flutuante; e a seguir com destaque das unidades de significados (US), que constituem palavras ou frases com sentido na perspectiva do fenômeno estudado. Após o destaque das US, estas foram interpretadas de acordo com sua convergência dentro do discurso de cada sujeito. E num segundo momento foi realizada a análise nomotética, na qual as unidades de significados elencadas foram agrupadas em unidades de significação para a articulação entre os diversos casos individuais, bem como análise de convergências, divergências e idiossincrasias, possibilitando a construção das categorias de análise. Com a finalidade de proteção dos entrevistados, os gestores foram identificados pela letra $\mathrm{G}$ seguida de um número $\left(\mathrm{G}_{1}, \mathrm{G}_{2}, \ldots, \mathrm{G}_{7}\right)$, e os prestadores pela letra $\mathrm{P}$ ( $\mathrm{P}_{1}$ e $\mathrm{P}_{2}$ ).

Quanto às questões éticas, a pesquisa respeitou a Resolução n ${ }^{0}$ 466/2012 do Conselho Nacional de Saúde (Brasil, 2013) e foi aprovada pelo Comitê de Ética em Pesquisa da instituição em que os pesquisadores estão vinculados, sob $n^{0} 1.700 .851$, em 29 de agosto de 2016.

\section{Resultados e discussão}

Da análise dos resultados emergiram três categorias, que envolvem a assistência médica especializada; aspectos resultantes da contratualização dos serviços e aspectos relacionados à gestão do sistema e dos serviços de saúde.

A primeira categoria aborda principalmente como a assistência médica, em especial a especializada, se articula com o setor público e faz com que ele oferte determinada ação ou serviço, impulsionado pela demanda.

A segunda categoria apresenta as fragilidades na contratualização dos serviços com o setor privado, entre eles a impossibilidade de executá-los com base na tabela SUS, e a contratação realizada entre gestores municipais com prestadores privados de municípios vizinhos, na contramão do comando único do sistema nacional de saúde. Apresenta também evidências que os contratos de média complexidade são pagos com os recursos que deveriam ser destinados à $\mathrm{AB}$.

Por fim, a terceira categoria se refere à gestão do sistema de saúde quanto aos aspectos macro e microrregionais (locais), como o financiamento insuficiente, a incipiente regulação do sistema de saúde local, e a identificação de barreiras para a expansão de serviços públicos de média complexidade no país.

\section{Assistência médica especializada}

A partir da fala dos participantes do estudo, destacaram-se características que influenciam os serviços contratualizados, os ofertados e a 
organização da demanda. Tal influência ocorre, sobretudo, pelo fato de o profissional médico do sistema público por vezes ser, também, o prestador privado das ASMC.

Na região, parte dos profissionais médicos que trabalham nos serviços públicos municipais, principalmente como generalistas na $\mathrm{AB}$, também possuem especialidade em determinada área, e atuam em clínicas e nos hospitais privados. A gente percebe que não existia uma demanda [específica] de exames. $E$ a partir do momento que ele [clínico] oferta aquele exame na clínica dele, cria essa demanda (G2).

Assim, de forma oportuna, alguns médicos solicitam aos usuários do SUS procedimentos diagnósticos e terapêuticos que eles, direta ou indiretamente, ofertam em seus vínculos de trabalho privado. Consequentemente, induzem o município a contratualizar procedimentos e serviços oferecidos, caracterizando-se assim como potenciais ordenadores das ASMC. Então o município acabava assumindo [a demanda] ali para conseguir resolver o problema do paciente, porque o paciente vai à porta do gestor, ele não vai à porta do governador e nem do secretário de Estado (G1).

Neste sentido os participantes do estudo referiram que o gestor do MPP se sente pressionado a ofertar estes serviços: o município tem que dar conta dessa demanda, demanda que se cria, e a gente não tem outra saída (G2).

Demanda é conceituada por Cecílio (2001, p. 4) como a "tradução de necessidades mais complexas do usuário", no entanto, para o mesmo autor, estas necessidades serão modeladas de acordo com a oferta disponível de consultas e procedimentos nos serviços de saúde.

Segundo Menicucci (2003), a compra de serviços do setor privado pelo ente público possibilitou a formação de interesses individuais e coletivos pelo financiamento público. Arretche (2003, p. 343) colabora afirmando que "se é verdade que os interesses privados se ajustam às estruturas estatais, não há porque duvidar que estes setores da indústria também tenham descentralizado suas estratégias de oferta de produtos" aos governos locais.

Para a perspectiva neoinstitucionalista histórica, esta ação é mediada pelas próprias instituições que modelam e possibilitam uma arena de condições para este tipo de prática (Pierson, 2004). Estas ações são reforçadas ainda pela "pressão da corporação farmacêutica, tecnológica, profissional e dos próprios pacientes" (Gérvas; Pérez Fernández, 2oo6, p. 66); estes últimos, baseados no comportamento coletivo (Menicucci, 2003) e na busca constante por procedimentos de alta densidade tecnológica (Carvalho et al., 2017).

Menicucci (2003) afirma que as relações públicoprivadas são complexas e conflitivas e, por isso, tornam a arena de saúde um espaço competitivo e contraditório, ao colocar o mesmo profissional sob formas distintas de inserção na assistência à saúde, na medida em que atuam tanto nos serviços públicos quanto nos privados.

Neste contexto, o profissional se beneficia dos dois sistemas, dependendo dos objetivos e retornos financeiros dos procedimentos executados em cada um deles, por exemplo, a venda de procedimentos de média complexidade ao ente público e a influência sobre a organização da demanda. Seria fundamental, portanto, discutir se os procedimentos diagnósticos e terapêuticos são necessários, ou se, na prática, vivese nos serviços de saúde o "excesso de rastreamentos, de solicitação de exames complementares e abusos na medicalização de fatores de risco" (Norman; Tresser, 2009, p. 2013).

Sobre isso deve-se considerar também aspectos relacionados à formação dos profissionais, característica que pode estar associada ao modelo flexneriano de ensino, o qual reduziu o indivíduo a um organismo biológico e gerou uma visão fragmentada do ser humano, gerando o alto custo dos serviços de saúde baseado em especializações e na incapacidade da formação em atender às reais demandas da população (Araújo; Miranda; Brasil, 2007).

Para contrapor esse modelo, a proposta de cuidado da Estratégia Saúde da Família (ESF) surge como uma possibilidade de atender às necessidades de saúde, entretanto o percentual de médicos especialistas em medicina da família no Brasil ainda é pequeno: $1,4 \%$ dos profissionais possuem o título de especialista em medicina da família e comunidade, estando presentes em apenas $5 \%$ dos serviços de saúde do país (Scheffer, 2018). Desta forma, na $\mathrm{AB}$, geralmente atuam médicos generalistas e/ou de variadas especialidades, que 
tendem a investigar a suspeita do usuário possuir alguma doença de sua especialidade, mesmo que essa não tenha sido a razão pela procura ao serviço de saúde, o que consequentemente incidirá sobre a demanda (Norman; Tresser, 2009).

E ainda há que se destacar a indução da demanda provocada pelo arranjo de grupos fechados de profissionais privados, muitos deles vinculados ao SUS, denominado pelos gestores entrevistados como o fenômeno de "reserva de mercado". Especialmente para média complexidade, [o problema] é a falta de profissionais. Acredito que a reserva de mercado por entidades privadas acabe realizando uma reserva forçada, bloqueando [outros] profissionais de exercerem a sua função [na região] (G3).

Esse fenômeno pode ser entendido como "algum limitador e/ou proteção" à entrada de outros serviços e profissionais na região. De acordo com os entrevistados, isso é observado quando profissionais de uma determinada especialidade impedem a entrada de outro profissional da mesma área, ao pressionar e impor regras e sanções aos hospitais e/ ou municípios contratantes. Utilizam-se da posição social e política de seus integrantes como estratégia para manter serviços públicos "dependentes" e demanda constante, além de determinar os valores dos procedimentos contratados, já que não há concorrência no mercado. Assim, o profissional novato, por não conseguir manter parceria com os hospitais privados, não permanece na região.

Sob outra perspectiva, os administradores hospitalares acreditam que alguns profissionais que atuam na assistência médica especializada não querem se comprometer com a demanda pública, utilizando o serviço público como forma de se estabilizar.

A partir de certo momento ele [médico] se desliga [do setor público], então ele tem usado o sistema público para autopromoção, ascensão, se tornar conhecido, se tornar um profissional de respeito, e até atingir esse ponto, [depois] ele deixa o sistema. (P1)

Percebe-se também que, ao mesmo tempo em que o prestador hospitalar culpabiliza o médico, há um contrassenso, pois os dois grupos juntos, administradores e profissionais médicos, constituem arranjos fechados "corporativistas" de assistência clínica na região e não permitem a entrada de profissionais oriundos de outros locais.

\section{Contratualização dos serviços}

Nesta dimensão identificaram-se aspectos resultantes dos contratos estabelecidos com o prestador privado e que incidem sobre a oferta e demanda na média complexidade. Tal prática resulta em contratos incoerentes com as normas do sistema, bem como em implicações causadas pela tabela SUS.

Os MPP realizam contratos com prestadores privados, ainda que estes estejam localizados em outro município e/ou sob gestão estadual. Dessa forma, os contratos estão em desacordo com a legislação, por ferir o comando único do sistema de saúde (Brasil, 1990). De acordo com esta premissa, o gestor do sistema de saúde é o único responsável por realizar/autorizar contratos entre um prestador de seu território e outro ente. Ocorre que os prestadores hospitalares dessa região estão sob gestão estadual, ou seja, possuem as ASMC contratualizadas com o estado. No entanto, devido à limitação da oferta, os municípios também celebram contrato com o mesmo prestador. Este segundo contrato, baseado em valores de mercado e envolvidos por interesses bilaterais, é chamado na região de "contrato paralelo".

Os contratos celebrados entre os MPP e os prestadores para custeio das ASMC consomem recursos expressivos do tesouro municipal (recursos próprios ou livres), uma vez que a gestão de recursos federais para a média e alta complexidade (MAC) é feita pelo estado. Assim, os municípios investem percentuais pequenos de seu orçamento na $A B$, que se mantém majoritariamente com as transferências da União, recebidas no fundo municipal de saúde. $\mathrm{Na}$ realidade o recurso especifico de média complexidade é [fonte] livre, não tem o que fazer né [...] não existe nenhum recurso vinculado que a gente possa utilizar pra custear a média $\left(\mathrm{G}_{3}\right)$.

Trevisan e Junqueira (2007) relatam que mais da metade dos MPP não arrecadam o suficiente para manter o executivo e o legislativo local, quanto mais para operacionalizar ações e serviços de saúde trazidos pelo processo de municipalização. 
Eu vejo que o nosso hospital municipal custa em torno de R\$ 420.ooo,oo por mês, se esses $R S$ 420.0oo,oo por mês fossem investidos na Atenção Básica, o quanto nós estaríamos na frente, o quanto nós estaríamos evoluídos, o quanto as equipes estariam fortalecidas. (G2)

Como consequência, isso gera um ciclo moldado pelos reduzidos investimentos, fazendo com que a $\mathrm{AB}$ aumente a demanda de encaminhamento de usuários para as ASMC. Com o alto consumo de exames e procedimentos diagnósticos, o município utiliza recursos financeiros próprios para realizálos, minimizando e precarizando os serviços na $A B$, e assim contribui novamente para o crescimento da demanda. Neste cenário, a AB sofre a disponibilização de serviços mínimos ou insuficientes para toda a complexa rede que sustenta (Brasil, 2014).

Na concepção neoinstitucional (Pierson, 2004), o financiamento das ASMC pelo ente municipal reforça (feedback positivo) a trajetória inicial da política de saúde que, em regiões formadas por MPP, ainda mantém o modelo anterior de compra de ASMC, apesar das mudanças possibilitadas pela Lei nº 8.080/1990 (Brasil, 1990), com a capilarização da $\mathrm{AB}$ e a pluralização de atores políticos, sociais e privados. Nestes municípios estes sujeitos participam e muitas vezes contribuem diretamente para a permanência desta relação.

Outro fator que desfavorece as ASMC pelo SUS por prestadores privados é o valor destinado aos procedimentos pela tabela vigente. Diversos autores (Spedo; Pinto; Tanaka, 2010; Trevisan; Junqueira, 2007) discutem as implicações trazidas ao sistema de saúde devido à ausência de reajustes na tabela, especialmente em relação aos valores atuais não serem atrativos para as ASMC; e também, apontam a tabela como um dos grandes problemas dos contratos e consequentemente do acesso às ASMC.

Na perspectiva desta pesquisa, a ausência de reajuste na tabela é vista como mais uma característica do engessamento e de reforço (feedback positivo) para a política inicial de compra de serviços de saúde pelo ente público - neste caso os MPP - via contrato paralelo. A não ser [...] que o prestador se sujeite a trabalhar com a tabela SUS, aí você pode usar o teto
MAC do município, como a gente não conhece ninguém que vai fazer isso (...) ( $\left.\mathrm{P}_{2}\right)$.

Observa-se também, na região, poucos esforços dos municípios para ofertar serviços compartilhados, caracterizados pelos conceitos de "financiamento solidário", "cooperação", "cogestão" (Brasil, 2006) e "economia em escala" (Mendes, 2019), constituindo elementos que fortaleceriam o processo de regionalização do sistema, se fossem desenvolvidos na prática dos serviços. Vale ressaltar, neste contexto, a importância do ente estadual quanto à coordenação e consolidação do processo de municipalização e gestão regional (Silva; Carvalho; Domingos, 2018).

Pestana e Mendes (2004) defendem que o processo de descentralização dos serviços de saúde no país se deu de forma autárquica, rápida e sem critérios estabelecidos, mantendo o financiamento dos serviços de saúde pela premissa do SUS universal, mas do Estado mínimo. Segundo os autores, o processo de regionalização deve seguir o princípio da responsabilização inequívoca, que significa definir e operar as responsabilidades dos entes federativos de forma que minimizem os conflitos de competência e traduzam um espaço de construção democrática.

Retornando ao conceito da "reserva de mercado", destaca-se que pela ausência de concorrência, a região estudada oferece serviços de saúde aos MPP exclusivamente pelo valor de mercado, assim, a disponibilidade de determinado serviço na região não é garantia de que ele será oferecido parcial ou integralmente, especialmente aqueles procedimentos de alto custo.

Neste contexto, prestadores privados somente disponibilizam para o ente público municipal os serviços mais rentáveis à sua instituição, impondo barreiras ao acesso de alguns procedimentos de média complexidade que consideram desvantajosos, o que pode ir contra as necessidades dos municípios, como mencionado na fala do gestor: eu pactuo [compro] a disponibilidade, nós trabalhamos com aquilo que tem disponivel, e o que tem disponível para o público $(\mathrm{G} 1)$.

Mendes (2019) afirma que o fenômeno de indução da demanda pela oferta ocorre quando as tecnologias em saúde disponíveis são utilizadas independentes das reais necessidades, apoiada pela relação não 
simétrica entre profissionais, usuários e prescritores de tecnologias. Nesse modelo de gestão da oferta, a organização de serviços é centrada nos prestadores e não nos usuários, muitas vezes estruturados por razões culturais, pela representação do poder político e por interesses de prestadores e da indústria da saúde.

Em outra perspectiva, prestadores privados sugerem que a demanda para as ASMC é resultado da ineficiência da $\mathrm{AB}$ nos municípios, como evidenciado na seguinte fala: infelizmente na maioria [dos municípios] a condição [da atenção básica] é ruim (P2). No entanto, sob outra perspectiva, considera-se a resolutividade da $\mathrm{AB}$ como variável dependente das ASMC, ou seja, não há como avaliar a AB sem a retaguarda possibilitada pela média complexidade.

\section{Gestão do sistema}

Esse estudo também possibilitou identificar aspectos referentes à gestão do sistema local e dos serviços de saúde que influenciam na oferta e demanda das ASMC, como o financiamento e o planejamento das necessidades locais.

Quanto ao recurso financeiro destinado às ASMC, constata-se em alguns municípios gastos com valor entre $45 \%$ e $80 \%$ da receita anual em serviços correspondentes às ASMC (Brasil, 2014), o que inclui também demandas provenientes de processos de judicialização.

o Ministério Público vem pra mim com um remédio, vai dar no fim do tratamento mais de 600 mil reais pro meu município, e isso era experimental, era experimental, não era nada definido que isso resolvia a questão [...] simplesmente paguei. $\left(\mathrm{G}_{4}\right)$

A judicialização da saúde no país apresentase pela lógica de que ela é um direito ilimitado, implicando ao poder público fornecer todo e qualquer procedimento de saúde ao cidadão. Os efeitos desse fenômeno comprometem partes significativas do orçamento público, principalmente nos MPP, o que acarreta grande impacto no orçamento (Fleury; Faria, 2014) e uso de expressiva parcela dos recursos próprios em ASMC, via ordem judicial.

Sob a ótica neoinstitucional (Pierson, 2004), o financiamento das ASMC pode ser analisado pela formação de grupos de interesse sobre o financiamento público, atualmente representado pelos atores que constituem a "bancada da saúde" no Congresso Nacional, cujos interesses são contraditórios, prevalecendo o poder das instituições privadas e filantrópicas, quando comparadas à garantia sobre o financiamento dos serviços públicos de saúde (Stevanin, 2015).

As consequências das deliberações da bancada são observadas na conjuntura microrregional (local) dos serviços de saúde e influenciam os investimentos em ASMC nas regiões de saúde. Além disso, os elementos que envolvem tais questões nesta região também são reflexos das políticas públicas anteriores de descentralização; municipalização desordenada e autárquica (Pestana; Mendes, 2004); hegemonia do modelo médico assistencial privatista (Carvalho et al., 2017); e das concepções neoliberais sobre a saúde coletiva (Viana; Fonseca; Silva, 2017). Neste sentido, pode-se interrogar por que, no Brasil, a rede pública de média complexidade não expandiu junto com os serviços de $\mathrm{AB}$ ?

Uma possível explicação para a ampliação da $A B$ é o fato de ter menor poder de compra sobre o sistema privado quando comparada à média complexidade; outra seria que a expansão de serviços públicos de média complexidade estaria na contramão dos interesses de organismos multilaterais no Brasil, como o Banco Mundial, que incentiva a participação privada nos serviços de saúde, principalmente pelo financiamento destinado aos governos subnacionais, reforçando a oferta e demanda para determinadas ASMC (Rizzoto; Campos, 2016).

Outro aspecto que interfere no acesso às ASMC é a regulação do sistema. A Organização Mundial da Saúde (OMS, 200o) considera a regulação uma função de governança dos sistemas de saúde, cabendo ao Estado ordenar as relações de produção e distribuição de recursos, bens e serviços de saúde. Neste sentido, a regulação deveria se basear em atividades de controle e auditoria exercidas principalmente sobre os prestadores privados contratados pelo sistema público, visando assegurar o acesso dos usuários em tempo oportuno, além de subsidiar o desenvolvimento de avaliação e planejamento das ações e serviços ofertados.

No entanto, com instrumentos de planejamento incipientes, os municípios não conseguem regular ou 
prever as necessidades de saúde de sua população, nem definir mecanismos de acesso às ASMC. Nos municípios analisados, a regulação assistencial ocorre sem critérios técnicos para os agendamentos, permeados de atravessamentos políticos e práticas clientelistas na relação com os usuários.

A regulação do acesso deveria ser entendida na região como meios e ações para garantir o direito constitucional ao acesso universal e integral à saúde, independente da pactuação estabelecida e/ ou disponibilidade de recurso financeiro, e definida por critérios técnicos pautados na equidade (Mendes, 2019). Hoje não tem [planejamento], a gente tenta fazer uma [regulação], mais não temos nada formalizado [...] esse é um ponto fraco do serviço aqui ( $\left.\mathrm{G}_{2}\right)$.

Entende-se, portanto, que esta categoria de análise é condicionada por aspectos apontados como consequências de características da macrogestão do sistema (como o financiamento da $\mathrm{AB}$ e a ampliação de programas coordenados pelo ente federal); por constrangimentos políticos causados pela ação de organismos multilaterais; e, principalmente, por aspectos da gestão local. Tais aspectos envolvem os contratos realizados com médicos que atuam nos serviços públicos e ofertam ASMC, e contratos com prestadores privados, evidenciados nas outras categorias mencionadas respectivamente.

As características referentes à gestão local em MPP se apresentam por meio de processos não implantados e/ou incipientes de avaliação, auditoria e regulação clínica assistencial. Estes elementos se comportam como vieses para um serviço de qualidade e contribuem para a má utilização dos recursos públicos.

Assim, com problemas reconhecidamente complexos, as três categorias de análise se relacionam devido à proximidade e diversidade de fatores que as compõem, destacando-se alguns pontos de intersecção (Figura 1).

Figura I - Aspectos que determinam e influenciam a oferta e demanda de ASMC

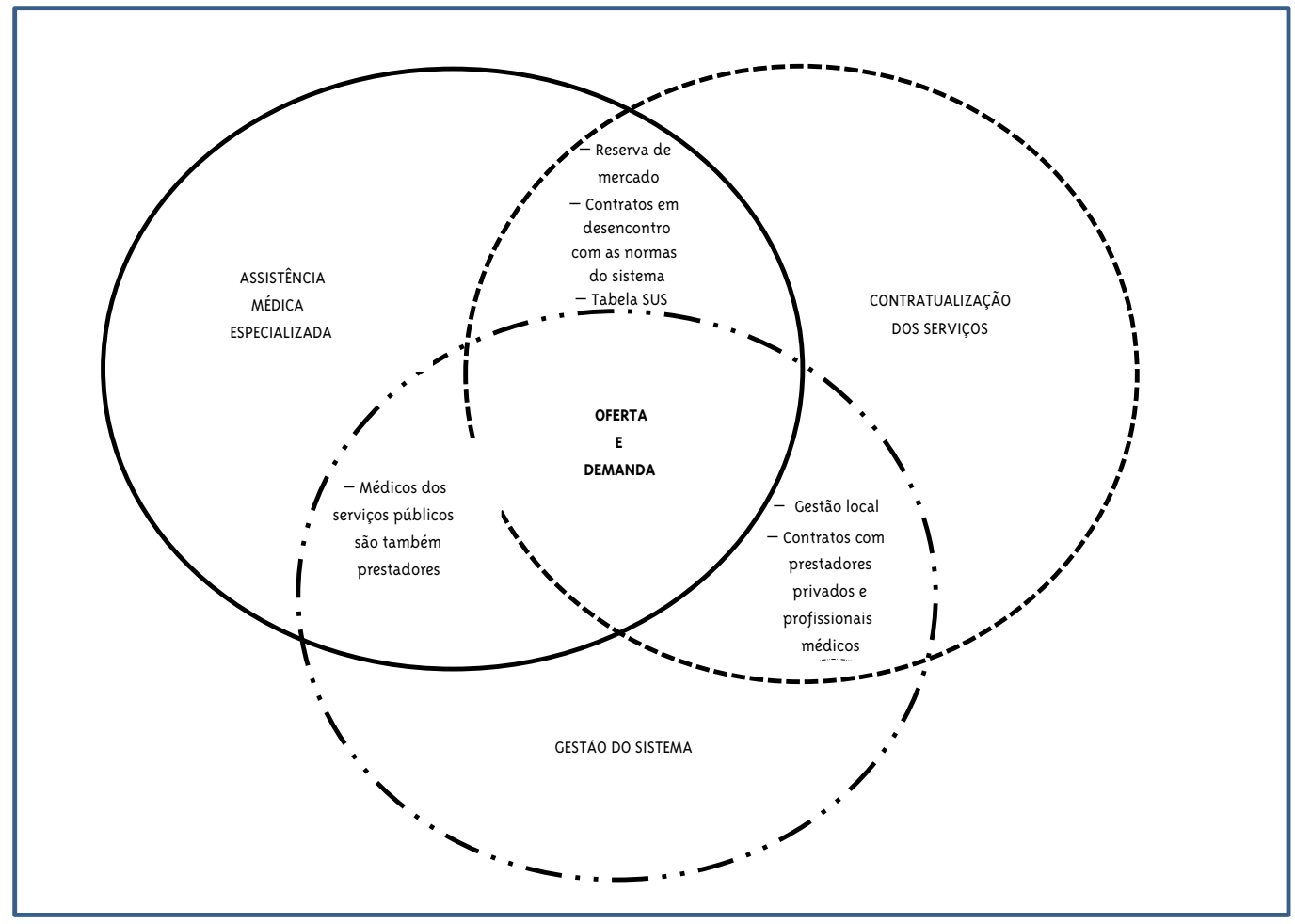


Quando a primeira categoria, assistência médica especializada, se interseciona com a categoria de contratualização, surge o fenômeno de "reserva de mercado": a institucionalização desta prática junto aos profissionais, e que necessita dos contratos para sua viabilização. Revelam-se também nesta intersecção os contratos paralelos e a lógica do pagamento por produção. Mas quando esta se relaciona com a categoria gestão do sistema, evidencia-se que o município compra procedimentos do mesmo profissional que os solicita, resultando no fato de o profissional médico do sistema público ser ao mesmo tempo o prestador privado das ASMC. Por fim, a intersecção entre a categoria contratualização e a categoria de gestão do sistema apresenta aspectos que demonstram a fragilidade dos contratos executados e dos mecanismos de regulação e planejamento, bem como a necessidade de aperfeiçoamento destes instrumentos.

\section{Considerações finais}

As características da relação público-privada em regiões formadas por MPP são reconhecidamente complexas e formadas por inúmeros fatores que não se esgotam neste manuscrito. Apesar disso, os elementos destacados neste recorte possibilitam a compreensão dessa relação e de seus efeitos sobre a oferta e a demanda de ASMC.

Na região estudada, a influência da relação público-privada sobre a oferta e a demanda das ASMC é determinada principalmente por fatores relacionados à assistência médica especializada, à contratualização dos serviços e à gestão do sistema e dos estabelecimentos de saúde. Verifica-se a priorização da gestão municipal em ações neste nível de atenção, em detrimento à $\mathrm{AB}$, fomentados principalmente pelo caráter político. Neste sentido, entende-se que a $A B$ se constitui como uma política preterida pelos gestores, mesmo com fortes evidências que seu fortalecimento incida diretamente na redução da demanda das ASMC.

Percebe-se a fragilidade do processo de regionalização, devido aos gestores municipais não desenvolverem alternativas coletivas aos problemas colocados, o que evidencia também a ausência do ente Estadual no processo de implementação das políticas de saúde na região pesquisada. Além disso, os incipientes ou quase nulos mecanismos de regulação contribuem ainda mais para a ampliação dos problemas elencados.

Soma-se ainda a este contexto um cenário preocupante, provocado por recentes ações contra o SUS, como a aprovação de uma emenda que congela ou limita por 20 anos os investimentos públicos em saúde, e alterações na Política Nacional de Atenção Básica (PNAB), as quais tendem a reforçar o modelo de atenção médica assistencialista e mudanças no financiamento das ações e serviços, via fundo nacional de saúde.

Para enfrentar estes problemas, recomendase que o setor público assuma o protagonismo que lhe é devido na regulação dos prestadores privados, fortalecendo a regulação clínica e assistencial e implantando serviços de auditorias regionais.

Quanto à contratualização de prestadores privados, uma alternativa seria fazer contratos coletivos, consorciados e por linha de cuidado, para a mesma finalidade regional. Essa estratégia fortaleceria a regionalização, na perspectiva que as ações coletivas tendem a alcançar melhores resultados com menor custo aos serviços de saúde, e ainda por compreender que as ASMC se constituem de uma responsabilidade tripartite.

Por fim, ressaltamos a necessidade de consolidação da $\mathrm{AB}$ como política prioritária do SUS, e da utilização de um setor complementar privado que atenda aos interesses da população usuária e à regulação dos entes públicos.

\section{Referências}

ARAÚJO, D.; MIRANDA, C. G.; BRASIL, S. L.

Formação de profissionais de saúde na perspectiva da integralidade. Revista Baiana de Saúde Pública, Salvador, v. 31, p. 20-31, 2007. Suplemento 1.

ARRETCHE, M. Financiamento federal e gestão local de políticas sociais: o difícil equilíbrio entre regulação, responsabilidade e autonomia. Ciência \& Saúde Coletiva, Rio de Janeiro, v. 8, n. 2,

p. 331-345, 2003. 
BRASIL. Presidência da República. Lei no 8.o8o, de 19 de setembro de 1990. Dispõe sobre as condições para a promoção, proteção e recuperação da saúde, a organização e o funcionamento dos serviços correspondentes e dá outras providências. Diário Oficial da União, Brasília, DF, 20 nov. 1990. Disponível em: <https://bit.ly/38xLboA>. Acesso em: 2 jan. 2017.

BRASIL. Ministério do Desenvolvimento Social e Combate à Fome. Secretaria Nacional de Assistência Social. Política Nacional de Assistência Social (PNAS) 2004 e Norma Operacional Básica (NOB/SUAS).

Brasília, DF, 2004.

BRASIL. Ministério da Saúde. Regionalização solidária e cooperativa: orientações para implementação no SUS. Brasília, DF, 2006. (Série Pactos pela Saúde, v. 3).

BRASIL. Conselho Nacional de Saúde. Resolução $\mathrm{n}^{\circ} 466$, de 12 de dezembro de 2012. Aprova normas regulamentadoras de pesquisas envolvendo seres humanos. Diário Oficial da União, Brasília, DF, 13 jun. 2013. Disponível em: <https://bit.ly/2BDb4Ac>. Acesso em: 3 out. 2016.

BRASIL. Sistema de Informação sobre Orçamento Público em Saúde. Relatório Anual de Gestão, 2014. Brasília, DF, 2014. Disponível em: <https://bit.ly/31XPPnd>. Acesso em: 15 dez. 2016.

BRASIL. Ministério da Saúde. Portaria nº 1.631, de $1^{\circ}$ de outubro de 2015. Aprova critérios e parâmetros para o planejamento e programação de ações e serviços de saúde no âmbito do SUS. Diário Oficial da União, Brasília, DF, 2 out. 2015. Disponível em: <https://bit.ly/2Z5vhaw>.

Acesso em: 2 maio 2020.

CARVALHO. B. G. et al. Organização do Sistema de Saúde no Brasil. In: ANDRADE M. A. et al. (Org.). Bases de saúde coletiva. Londrina: Ed. UEL, 2017. p. 47-91.

CECÍLIO, L. C. O. As necessidades de saúde como conceito estruturante na luta pela integralidade e equidade da atenção. In: PINHEIRO, R.; MATTOS, R. A. Os sentidos da integralidade na atenção e no cuidado à saúde. Rio de Janeiro, IMS Abrasco, 2001. p. 113-126.
FLEURY, S.; FARIA, M. A judicialização como ameaça e salvaguarda do SUS! In: SANTOS, L.; TERRAZAS, F. (Org.). Judicialização da saúde no Brasil. Campinas: Ed. Saberes, 2014.

GÉRVAS, J.; PÉREZ FERNÁNDEZ, M. Uso y abuso del poder médico para definir enfermedad y factor de riesgo, em relación con la prevención cuaternaria. Gaceta Sanitaria, Barcelona, v. 20, p. 66-71, 2006. Suplemento 3.

LIMA, L. D. et al. Arranjos regionais de governança do Sistema Único de Saúde: diversidade de prestadores e desigualdade espacial na provisão de serviços. Cadernos de Saúde Pública, Rio de Janeiro, v. 35, p. eooog4618, 2019. Suplemento 2.

MARTINS, J.; BICUDO, M. A. V. A pesquisa qualitativa em psicologia: fundamentos e recursos didáticos. São Paulo: Centauro, 2003.

MENDES, E. V. Desafios do SUS. Brasília, DF: Conass, 2019.

MENICUCCI, T. M. G. Público e privado na política de assistência à saúde no Brasil: atores, processos e trajetória. 2003. Tese (Doutorado em Sociologia e Política), Universidade Federal de Minas Gerais, Belo Horizonte, 2003.

NORMAN, A. H.; TRESSER, C. D. Prevenção quaternária na atenção primária à saúde: uma necessidade do sistema único de saúde. Cadernos de Saúde Pública, Rio de Janeiro, v. 25, n. 9, p. 2012-2020, 2009.

OMS - ORGANIZAÇÃO MUNDIAL DA SAÚDE. Relatório sobre a saúde no mundo 2000 melhorar o desempenho dos sistemas de saúde. Genebra, 2000.

PESTANA, M.; MENDES, E. V. Pacto de gestão: da municipalização autárquica à regionalização cooperativa. Belo Horizonte: Secretaria de Estado de Saúde, 2004.

PIERSON, P. Politics in time: history, institutions, and social analysis. Princeton: Princeton University Press, 2004.

RIZZOTTO, M. L. F.; CAMPOS, G. W. S. O Banco Mundial e o Sistema Único de Saúde brasileiro no 
início do século XXI. Saúde e Sociedade, São Paulo, v. 25, n. 2, p. 263-276, 2016.

SCHEFFER, M. et al. Demografia Médica no Brasil 2018. São Paulo: FMUSP, 2018.

SILVA, J. F. M.; CARVALHO, B. G.; DOMINGOS, C. M. A governança e a relação público-privado no cotidiano das práticas em municípios de pequeno porte. Ciência \& Saúde Coletiva, Rio de Janeiro, v. 23, n. 10, p. 3179-3188, 2018.

SPEDO, S. M.; PINTO, N. R. S.; TANAKA, O. Y. O difícil acesso a serviços de média complexidade do SUS: o caso da cidade de São Paulo, Brasil. Physis, Rio de Janeiro, v. 20, n. 3, p. 953-972, 2010.

STEVANIN, L. F. Vozes da saúde no legislativo. Radis, Brasília, DF, n. 156, p. 14-23, 2015.
TREVISAN, L. M.; JUNQUEIRA L. A. P.

Construindo o "pacto de gestão" no SUS: da descentralização tutelada à gestão em rede. Ciência \& Saúde Coletiva, Rio de Janeiro, v. 12, n. 4, p. 893-902, 2007.

VIANA, A. L. D.; FONSECA, A. M. M.; SILVA, H. P. Proteção social na América Latina e Caribe: mudanças, contradições e limites. Cadernos de Saúde Pública, Rio de Janeiro, v. 33, p. eoo216516, 2017. Suplemento 2.

VIANA, A. L. D. et al. O processo de regionalização no Brasil: influência das dimensões política, estrutura e organização. Revista Brasileira de Saúde Materna Infantil, Recife, v. 17, p. S27-S43, 2017. Suplemento 1.

\section{Contribuição dos autores}

Silva e Carvalho participaram igualmente de todas as etapas da elaboração do artigo. Domingos participou da concepção do texto. Mendonça contribuiu com a revisão, apresentando sugestões $e$ redigindo trechos da versão final.

Recebido: 19/05/2020

Aprovado: 28/06/2020 